\title{
PI-MPC Frequency Control of Power System in the Presence of DFIG Wind Turbines
}

\author{
Michael Z. Bernard ${ }^{1}$, T. H. Mohamed ${ }^{2}$, Raheel Ali ${ }^{1}$, Yasunori Mitani ${ }^{1}$, Yaser Soliman Qudaih ${ }^{1}$ \\ ${ }^{1}$ Department of Electrical Engineering and Electronics, Kyushu Institute of Technology, Fukuoka, Japan \\ ${ }^{2}$ Faculty of Energy Eng., Aswan University, Aswan, Egypt \\ Email: mzbernard@yahoo.com, tarekhie@yahoo.com, raheel.ali@hotmail.co.jp, \\ mitani@ele.kyutech.ac.jp, yaser_qudaih@yahoo.com
}

Received July 2013

\begin{abstract}
For the recent expansion of renewable energy applications, Wind Energy System (WES) is receiving much interest all over the world. However, area load change and abnormal conditions lead to mismatches in frequency and scheduled power interchanges between areas. These mismatches have to be corrected by the LFC system. This paper, therefore, proposes a new robust frequency control technique involving the combination of conventional Proportional-Integral (PI) and Model Predictive Control (MPC) controllers in the presence of wind turbines (WT). The PI-MPC technique has been designed such that the effect of the uncertainty due to governor and turbine parameters variation and load disturbance is reduced. A frequency response dynamic model of a single-area power system with an aggregated generator unit is introduced, and physical constraints of the governors and turbines are considered. The proposed technique is tested on the single-area power system, for enhancement of the network frequency quality. The validity of the proposed method is evaluated by computer simulation analyses using Matlab Simulink. The results show that, with the proposed PI-MPC combination technique, the overall closed loop system performance demonstrated robustness regardless of the presence of uncertainties due to variations of the parameters of governors and turbines, and loads disturbances. A performance comparison between the proposed control scheme, the classical PI control scheme and the MPC is carried out confirming the superiority of the proposed technique in presence of doubly fed induction generator (DFIG) WT.
\end{abstract}

Keywords: Doubly Fed Induction Generator; Power System; Model Predictive Control); Proportional Integral Controller; DFIG Wind Turbine; Wind Energy System (WES)

\section{Introduction}

Two balances corresponding to two equilibrium points namely frequency and voltage must be maintained between generation and utilization in an electric power system. This enables generation and distribution of quality electrical power to factories and homes. Breaking or resetting either of the two balances to a new level will constitute floating of the equilibrium points. When either of the two balances is broken and reset at a new level, the equilibrium points will float. A good-quality electric power system requires both the frequency and voltage to remain at standard values during operation.

Thus a control system is important to mitigate the effects of the random load changes and keep the frequency and voltage at the standard values. Although active and reactive power affects the frequency and voltage respectively, the frequency is highly dependent on the active power while the voltage is highly dependent on the reactive power. Thus the control issue in power systems can be decoupled into two independent problems. One is about the active power and frequency control while the other is about the reactive power and voltage control. The active power and frequency control is referred to as load frequency control (LFC) [1] which is the major concern of this paper.

LFC objectives, which determine the LFC synthesis as a multi-objective optimization problem [2,3] are concerned with, frequency regulation and tracking the load demands, maintaining the tie-line power interchanges to specified values in the presence of modeling uncertainties, system nonlinearities and area load disturbances. Hence, Frequency control or Load frequency control is an important function of power system operation where the main objective is to regulate the output power of each generator at prescribed levels while keeping the frequency fluctuations within pre-specified limits [4].

On the other hand, energy problems and environmental issues have led to, with recent expansion of renewable energies, power systems. WES is the fastest growing and mostly utilized of all the renewable energies and its 
global production is predicted to grow to 300GW in 2015 [5]. Hence, WES connected to the power systems has created serious interest and concern among researchers. In several research works, for example, in [2] it was pointed out that the renewable integration impacts are non-zero and can become more significant at higher size of penetrations.

Variable speed wind turbines (VSWTs) are the most utilized type of modern WTs. They are partially or totally decoupled from the power network due to the power electronic converters which limits their capacity to provide primary frequency support to the network in case of disturbances. The inertial response of WTs is discussed in details as in [6,7]. A detailed background of frequency responses, including primary and secondary responses provided in [6] where detailed comparison between fixed-speed wind turbines (FSWTs) and doubly fed induction generator (DFIG) type WTs is shown through detailed simulations, showing that FSWTs and DFIGbased WTs can contribute to frequency response. In [7], it is reported that full converter (FC) type WTs are completely decoupled from the power grid and no contribution is given to the frequency regulation but pointed out that DFIG-type WTs have some small contribution to the power network. In the work, it is assumed that the VSWTs have negligible inertial response and that additional control loop is necessary for a proper machine inertial response.

Control system designers today are applying different control algorithms in order to find the best controller parameters for optimum solutions. While some of these methods are very successful for special cases but unsuccessful for other general applications, many control strategies have been proposed and investigated by several researchers for LFC design of power systems [8-11]. Robust adaptive control schemes have been developed in [3,12-16] to deal with changes in system parameters. Fuzzy logic controllers have been used in many reports for LFC design in a two area power system [17], with and without nonlinearities. The applications of artificial neural network, genetic algorithms, and optimal control to LFC have been reported in $[18,19]$. In their findings, it is observed that the transient response is oscillatory and it seems that some other elegant techniques are needed to achieve a desirable performance.

Fixed parameters controllers, such as PI controllers, are also widely employed in the LFC application. Fixed parameters controllers are designed at nominal operating points and may no longer be suitable in all operating conditions. For this reason, adaptive gain scheduling approaches have been proposed for LFC synthesis $[12,13]$. This method overcomes the disadvantages of the conventional PI controllers, which needs adaptation of controller parameters, but actually, it faces some difficulties, like the instability of transient response as a result of abrupt changes in the system parameters in addition to the impossibility of obtaining accurate linear time invariant models at variable operating points [12]. In [20-23], fast response and robustness against parameter uncertainties and load changes can be obtained using MPC controller for single area load frequency control application, but without WT participation. However, in [24] a new load frequency control (LFC) using the model predictive control (MPC) technique in the presence of wind turbines (WT) was presented and the results demonstrated that the closed-loop system with MPC controller is robust against the parameter perturbation of the system and has more desirable performance in comparison with classical integral control design in all of the tested scenarios. Also, it was denoted that wind turbine has a positive effect on the total response of the system.

Though several optimal and robust control strategies have been developed for LFC, they all required suggested replacement of the traditionally integral or PI controller with a new robust control scheme. But instead of replacing the conventional controller with a robust control scheme, this paper proposes a new robust control technique involving the combination of a conventional PI controller and a robust controller, precisely, the MPC, to form a single controller known as the PI-MPC technique for power system frequency control. This technique is more economical, so that, a single PI-MPC scheme will produce a stronger control signal to control the entire area rather than using multiple controllers nor removing or replacing traditional controllers already in the system. This works since the MPC adapts well to different physical setups and allows for a unified approach [22-24] while PI controller can have zero steady state error though its disadvantage has to do with maximum overshoot and high settling time plus inability to adapt to different changes in system parameters [22]. The respective PI and MPC controllers may not be new but the combination of these two control schemes to form a single controller is completely new in power system research.

In this paper, the load frequency control for a single area power system in the presence of WES has been developed based on the PI-MPC technique. Each local area includes an aggregated wind turbine model (which consists of 200 wind turbine units) beside the main generation unit. With the PI-MPC technique, the MPC produces its optimal output derived from a quadratic cost function minimization based on the dynamic model of the single area power system which combines with the PI signal. The technique calculates the optimal control signal while respecting the given constrains over the output frequency deviation and the load change. The effects of the physical constraints such as generation rate constraint (GRC) and speed governor dead band are considered [20]. The power 
system with the proposed PI-MPC technique has been tested through the effect of uncertainties due to governor and turbine parameters variation and load disturbance using computer simulation. A comparison has been made between the proposed PI-MPC controller, the traditional PI controller and MPC, confirming the superiority of the proposed technique. The simulation results proved that the proposed controller can be applied successfully to the application of power system frequency control including that with WT. The rest of the paper is organized as follows: General overview of MPC and its cost function are presented in Section 2. In Section 3, the simplified wind turbine model, the description of the dynamics of the power system and the overall structure of the implementation scheme as a single area power system together with the PI-MPC technique are explained. Simulation results and general remarks are presented in Section 4. Finally, the paper is concluded in Section 4.

\section{General Overviewmpc}

The MPC has proved an efficient control in a wide range of applications in industry such as chemical process, petrol industry, electromechanical systems and many other applications. Figure 1 below illustrates a Simple structure of MPC controller.

The MPC scheme uses a prediction model of the system response to obtain the control actions by minimizing an objective function. The objective of the optimization is to minimize the difference between the predicted and reference response, and the control effort subjected to prescribed constraints.

The effectiveness of MPC is equivalent to optimal control. At each control interval, the first input in the optimal sequence is sent into the plant, and the entire calculation is repeated at subsequent control intervals. The purpose of taking new measurements at each time step is to compensate for unmeasured disturbances and model inaccuracy, both of which cause the system output to be different from the one predicted by the model $[14,15]$.

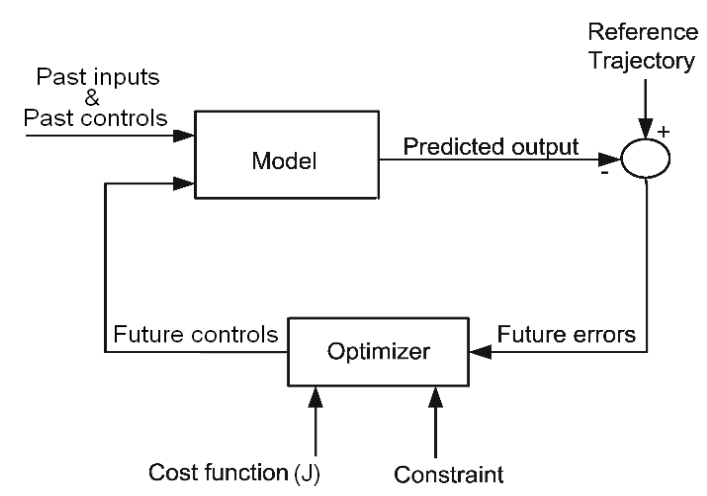

Figure 1. Simple structure of MPC.
An internal model is used to predict the future plant outputs based on the past and current values of the inputs and outputs and on the proposed optimal future control actions. The prediction has two main components: the free response which being expected behavior of the output assuming zero future control actions, and the forced response which being the additional component of the output response due to the candidate set of future controls. For a linear system, the total prediction can be calculated by summing both of free and forced responses. The reference trajectory signal is the target values the output should attain. The optimization is subject to constraints on both manipulated and controlled variables [22]. The general object is to tighten the future output error to zero, with minimum input effort. Therefore, the optimizer calculates the best set of future control action by minimizing a cost function $(\mathrm{J})$ which is generally a weighted sum of square predicted errors and square future control values, e.g. in the Generalized Predictive Control (GPC):

$$
\begin{aligned}
\mathrm{J}\left(N_{1} N_{2} N_{3}\right) & =\sum_{j=N_{1}}^{N_{2}} \beta(j)\left[\hat{y}(k+j / k)-\omega(k+j)^{2}\right] \\
& +\sum_{j=1}^{N_{u}} \lambda(j)\left[u(k+j-1)^{2}\right]
\end{aligned}
$$

where $\mathrm{N}_{1}$ and $\mathrm{N}_{2}$ are the lower and upper prediction horizons over the output, $\mathrm{N}_{\mathrm{u}}$ is the control horizon, $\beta j(), \lambda j$ ) are weighting factors. The control horizon permits to decrease the number of calculated future control according to the relation:

$\Delta u(K+j)=0$ for $j \geq N_{u}$ and $\omega(K+j)$ represents the reference trajectory over the future horizon $N$. Constraints over the control signal, the outputs and the control signal changing can be added to the cost function as follows:

$$
\begin{aligned}
& \mathrm{u}_{\text {min }} \leq \mathrm{u}(\mathrm{k}) \leq \mathrm{u}_{\text {max }} \\
& \Delta \mathrm{u}_{\text {min }} \leq \Delta \mathrm{u}(\mathrm{k}) \leq \Delta \mathrm{u}_{\text {max }} \\
& \mathrm{y}_{\text {min }} \leq \mathrm{y}_{\mathrm{k}} \leq \mathrm{y}_{\text {max }}
\end{aligned}
$$

Details of MPC are discussed in [22-24].

\section{System Configuration}

\subsection{System Dynamics}

In this section, a simplified frequency response model for a single area power system with an aggregated generator unit is described [2].

The overall generator-load dynamic relationship between the incremental mismatch power $\Delta P_{m}-\Delta P_{L}$ and the frequency deviation $\Delta f$ can be expressed as:

$$
s . \Delta f=\left(\frac{1}{2 H}\right) \cdot \Delta P_{m}-\left(\frac{1}{2 H}\right) \cdot \Delta P_{L}-\left(\frac{D}{2 H}\right) \cdot \Delta f
$$


While the dynamics of the governor can be expressed as:

$$
s \cdot \Delta P_{m}=\left(\frac{1}{T_{t}}\right) \cdot \Delta P_{g}-\left(\frac{1}{T_{t}}\right) \cdot \Delta P_{m}
$$

and the dynamics of the turbine can be expressed as:

$$
s \cdot \Delta P_{g}=\left(\frac{1}{T_{g}}\right) \cdot \Delta P_{c}-\left(\frac{1}{R \cdot T_{g}}\right) \cdot \Delta f-\left(\frac{1}{T_{g}}\right) \cdot \Delta P_{g}
$$

The block diagrams of the past equations are included in Figure 2 where:

$\Delta P_{g}$ : Change in the governor out put

$\Delta P_{m}$ : Change in mechanical power

$\Delta f:$ Frequency deviation

$\Delta P_{L}$ : The load change

$\Delta P_{c}$ : Supplementary control action

$H$ : Equivalent inertial constant

$D$ : Equivalent damping coefficient

$R$ : Speed drop characteristics

$T_{g}$ and $T_{t}$ : are governor and turbine time constant respectively.

\subsection{Simplified Wind Turbine Model for Frequency Studies}

Figure 3 above shows a simplified model of DFIG based wind turbine (WT) for frequency response [24]. This simplified model can be described by the following equations:

$$
s i_{q r}=-\left(\frac{1}{T_{1}}\right) \cdot \mathrm{i}_{q r}+\left(\frac{\mathrm{X}_{2}}{\mathrm{~T}_{1}}\right) \cdot \mathrm{V}_{\mathrm{qr}}
$$

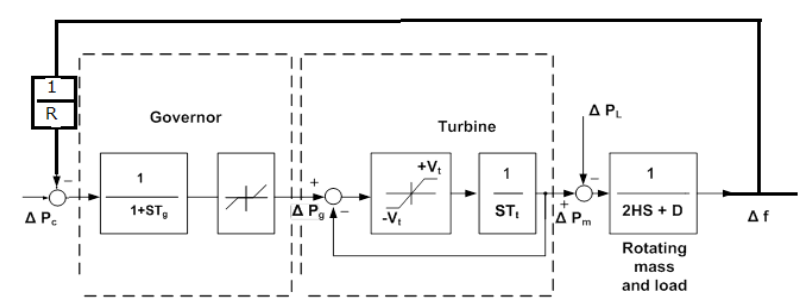

Figure 2. The block diagram of a single area power system

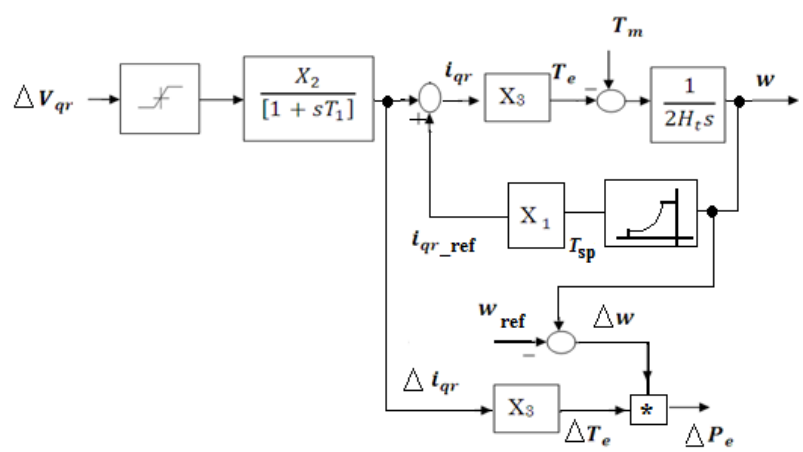

Figure 3. Simplified model of DFIG based wind turbine [19].

$$
\begin{aligned}
& s . \omega=-\left(\frac{X_{3}}{2 H_{t}}\right) \cdot i_{q r}+\left(\frac{X_{2}}{2 H_{t}}\right) \cdot T_{m} \\
& P_{e}=\omega \cdot X_{3} \cdot i_{q r}
\end{aligned}
$$

For linearization, Equation (14) can be rewritten as:

$$
P_{e}=\omega_{o p t} \cdot X_{3} \cdot i_{q r}
$$

where $\omega_{\text {opt }}$ is the operating point of the rotational speed, $S$ is the differential operator, $T_{e}$ is the electromagnetic torque, $T_{m}$ is the mechanical power change, $\omega$ is the rotational speed, $P_{e}$ is the active power of wind turbine, $\mathrm{i}_{\mathrm{qr}}$ is q-axis component of the rotor current, $\mathrm{V}_{\mathrm{qr}}$ is q-axis component of the rotor voltage and $H_{t}$ is the equivalent inertia constant of wind turbine. Table 1 shows the detailed expressions of the main parameters utilized for the simplified model of Figure 3.

Where:

$$
\begin{aligned}
& L_{0}=L_{r r}+\frac{L_{m}^{2}}{L_{s s}} \\
& L_{s s}=L_{s}+L_{m} \\
& L_{r r}=L_{r s}+L_{m}
\end{aligned}
$$

$\omega_{s}$ is synchronous speed, $L_{m}$ is the magnetizing inductance, $R_{r}$ and $R_{s}$ are the respective rotor and stator resistances, $L_{r}$ and $L_{s}$ are the rotor and stator leakage inductances respectively, while $\mathrm{L}_{\mathrm{rr}}$ and $\mathrm{L}_{\mathrm{ss}}$ are the rotor and stator self-inductances respectively.

\section{Overall System Structure}

The block diagram of a simplified frequency response model for a single area power system with aggregated unit including the proposed PI-MPC controller is shown in Figure 4.

The system consists of the rotating mass and load, nonlinear turbine with GRC, and governor with deadband constraint [1].

The frequency deviation is used as feedback for the closed loop control system. Initially, a PI controller in the system receives the frequency signal $\Delta \mathrm{f}$, to be controlled, and hence produces the supplementary action $\Delta P_{c}$. Then, in an effort to improve system performance, the measured and reference frequency deviation $\Delta f_{\text {ref }}$ (where $\Delta f_{\text {ref }}=0 \mathrm{~Hz}$ ) and the reference wind rotational speed, $\Delta \omega_{\text {ref }}$, where, $\left(\omega_{\text {ref }}=\omega_{\text {opt }}\right)$ are fed to the MPC controller in order to obtain the supplementary control action $\Delta \mathrm{P}_{\mathrm{c}}$. This control action $\Delta \mathrm{P}_{\mathrm{c}}$, is then added to

Table 1. Parameters for Figure 3 [24].

\begin{tabular}{ccc}
\hline$X_{2}$ & $X_{3}$ & $\mathrm{~T}_{1}$ \\
\hline$\frac{1}{R_{T}}$ & $\frac{L_{m}}{L_{s s}}$ & $\frac{L_{0}}{\omega_{s} R_{s}}$ \\
\hline
\end{tabular}


$\Delta \mathrm{P}_{\mathrm{c}}$. The resulting signal of the PI-MPC which is simply the combination of the signals due to the PI and MPC controllers respectively: $\Delta \hat{\mathrm{P}}_{\mathrm{c}}=\Delta \mathrm{P}_{\mathrm{c}}+\Delta \tilde{\mathrm{P}}_{\mathrm{c}}$ is fed to the governor, giving the governor valve position which supplies the turbine to give the mechanical power change $\Delta \mathrm{P}_{\mathrm{m}}$. Both the active power change of wind turbine $\Delta \mathrm{P}_{\mathrm{e}}$ and the load change $\Delta \mathrm{P}_{\mathrm{L}}$ affect the mechanical power change giving the input of the rotating mass and load block to provide actual frequency deviation $\Delta f$.

\section{Results and Discussion}

In order to validate the effectiveness of the proposed scheme Computer simulations have been carried out in the Matlab/Simulink environment. A practical single area power system has the following nominal parameters [2] listed below in Table 2 .

Simulation studies are carried out for the proposed controller with generation rate constraint (GRC) of $10 \%$ p.u. per minute. The maximum value of dead band for governor is specified as $0.05 \%$. The parameters of the MPC controller are set as follows:

Prediction horizon $=10$, Control horizon $=2$, Weights on manipulated variables $=0$, Weights on manipulated variable rates $=0.1$, Weights on the output signals $=1$ and Sampling interval $=0.0003$ sec. Constraints are imposed over the control action, and frequency deviation. They are considered as follows:

Max. control action $=0.25 \mathrm{pu}$, Min. control action $=$ $0.25 \mathrm{pu}$,

Max. frequency deviation $=0.25 \mathrm{pu}$, and Min. frequency deviation $=-0.25 \mathrm{pu}$.

The wind turbine field consists of 200 units of 2MW rated variable speed wind turbine VSWTs, the wind turbine parameters and operating point are indicated in Table 3.

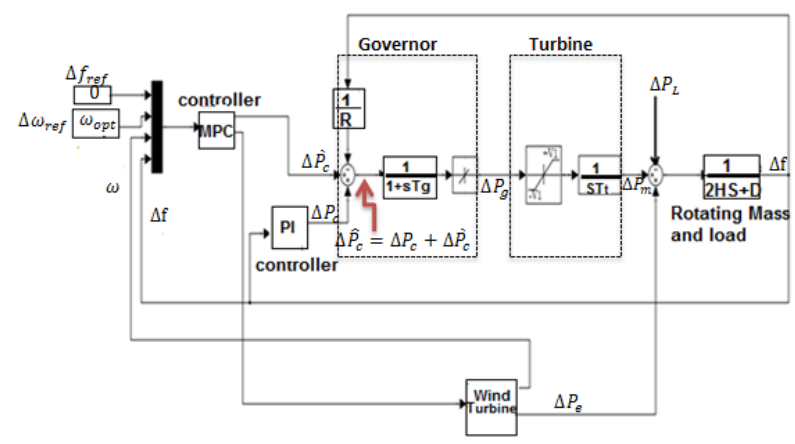

Figure 4. The block diagram of a single area power system including the proposed PI-MPC controller

Table 2. Parameters and data of a practical single area power system.

\begin{tabular}{ccccc}
\hline $\mathrm{D}(\mathrm{p} . \mathrm{u} / \mathrm{Hz})$ & $\mathrm{H}$ (pu.sec) & $\mathrm{R}(\mathrm{Hz} / \mathrm{p} . \mathrm{u})$ & $T_{g}(\mathrm{sec})$ & $T_{t}$ (sec) \\
\hline 0.015 & 0.08335 & 3.00 & 0.08 & 0.4 \\
\hline
\end{tabular}

Table 3. Wind turbine parameters and operating point [25].

\begin{tabular}{ccc}
\hline $\begin{array}{c}\text { Operating } \\
\text { point }(\mathbf{m w})\end{array}$ & $\begin{array}{c}\text { Wind } \\
\text { speed }(\mathbf{m} / \mathbf{s})\end{array}$ & $\begin{array}{c}\text { Rotational } \\
\text { speed }(\mathbf{m} / \mathbf{s})\end{array}$ \\
\hline 247 & 11 & 1.17 \\
$R_{r}(\mathbf{p u})$ & $R_{s}(\mathbf{p u})$ & $\mathrm{X}_{l r}(\mathbf{p u})$ \\
0.00552 & 0.00491 & 0.1 \\
$\mathrm{X}_{l s}(\mathbf{p u})$ & $\mathrm{X}_{m}(\mathbf{p u})$ & $H_{t}(\mathbf{p u})$ \\
0.09273 & 3.9654 & 4.5 \\
\hline
\end{tabular}

$\mathrm{X}_{\mathrm{m}}$ is the magnetizing reactance while $\mathrm{X}_{\mathrm{lr}}$ and $\mathrm{X}_{\mathrm{ls}}$ are the leakage reactance of the rotor and stator respectively.

For the simulations studies, three cases are investigated. The first case is a nominal case where the power system operates under normal operating conditions. The second case the changed case where changes are made in the parameters of the power system so as to carry out robustness investigations and comparison is made between the controllers. In the third case, the effect of WT on the power system frequency is investigated considering variable wind speed. The parameters of the PI controller are $\mathrm{K}(\mathrm{p})=0.37$ and $\mathrm{K}(\mathrm{s})=-0.745$.

\subsection{First Case:System Performance at Nominal Case}

The system performance with the proposed PI-MPC controller during WT participation at nominal parameters is tested and comparison is made between the system performances with conventional proportional integrator K(p) $=0.37$ and $\mathrm{K}(\mathrm{s})=-0.745 / \mathrm{s}$ in the presence of a step load change $\Delta P_{L}=0.02$ p.u. at $t=30$ sec. Figure 5 shows the simulation results of the proposed PI-MPC, MPC and only conventional PI systems. The results from the top to the bottom are: the mechanical power change, $\Delta \mathrm{P}_{\mathrm{m}}$, in per unit, the frequency deviations, $\Delta f$, in Hertz and the governor's controlled input signals, $\Delta \mathrm{P}_{\mathrm{s}}$, in per unit. It can be seen that after a step load changed is experienced by the system at $\mathrm{t}=30 \mathrm{sec}$, the conventional integral controller gradually brings the system back to its reference point but took a much longer time. With the proposed PI-MPC controller, the system is more stable and faster as compared to the system with MPC only or conventional PI controller only.

\subsection{Second Case: Robustness Evaluation}

To evaluate the robustness of the proposed PI-MPC technique, changes are made in the parameters of the power system by increasing the governor and turbine time constants to $T_{g}=0.12 \mathrm{sec}$ and $T_{t}=0.95 \mathrm{sec}$, respectively. 


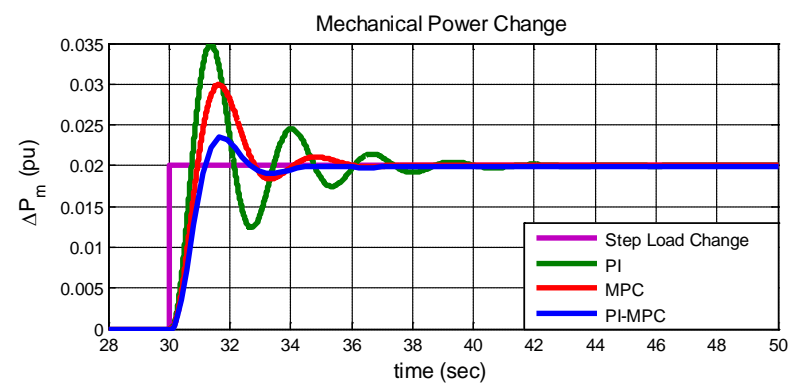

(a)

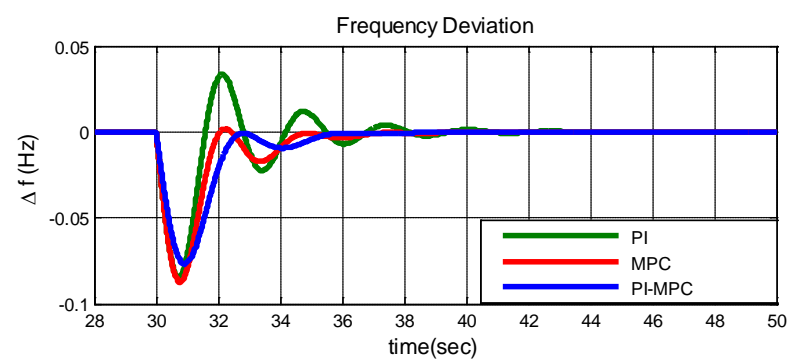

(b)

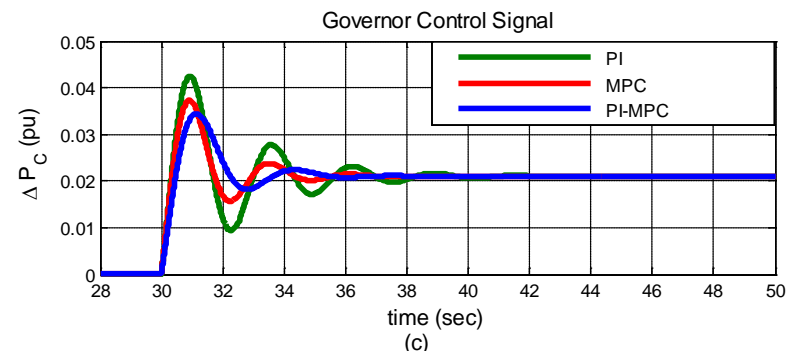

Figure 5. Power system response to a small load change a) Mechanical power change, b) frequency deviation and c) governor's control signal.

Figure 6 depicts the system response with the respective PI, MPC and PI-MPC control schemes during this case of study. The load change is assumed to be as described in the first case. It has been shown that, with the traditional controller, the system becomes unstable while with MPC controller, the system response is more enhanced. However, it can be seen that the PI-MPC is much faster in damping the power system oscillations and hence yields the most desirable result in enhancement of the system frequency by displaying robust characteristics in the presence of load change and parameters uncertainties.

\subsection{Third Case: Variable Wind Speed}

In order to further test the effectiveness of the proposed PI-MPC control technique. Figure 7 shows the variable wind speed pattern in the presence of which the simulation was performed. It can be seen that the wind speed initially $12.5 \mathrm{~m} / \mathrm{s}$ fluctuates between $10 \mathrm{~m} / \mathrm{s}$ to $15 \mathrm{~m} / \mathrm{s}$. The simulation was performed in the presence of variable wind speed and the system is observed. From Figure 8, it

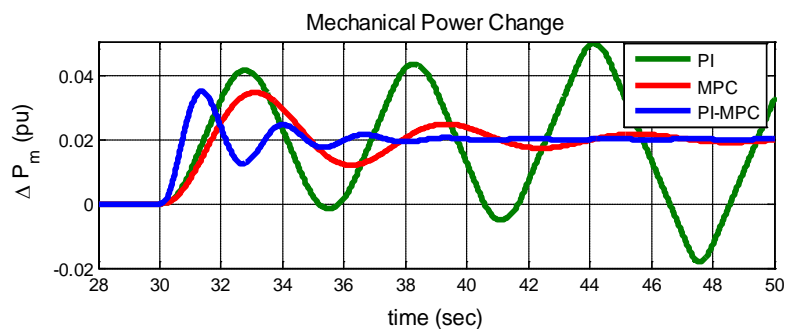

(a)

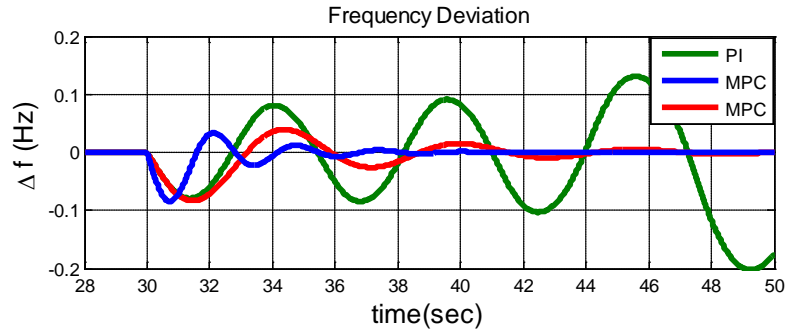

(b)

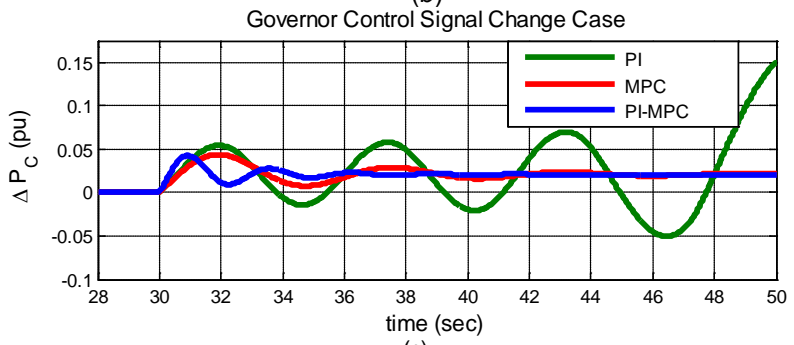

(c)

Figure 6. Power system response to different changes: (a) Mechanical power change, (b) frequency deviation and (c) governor's control signal.

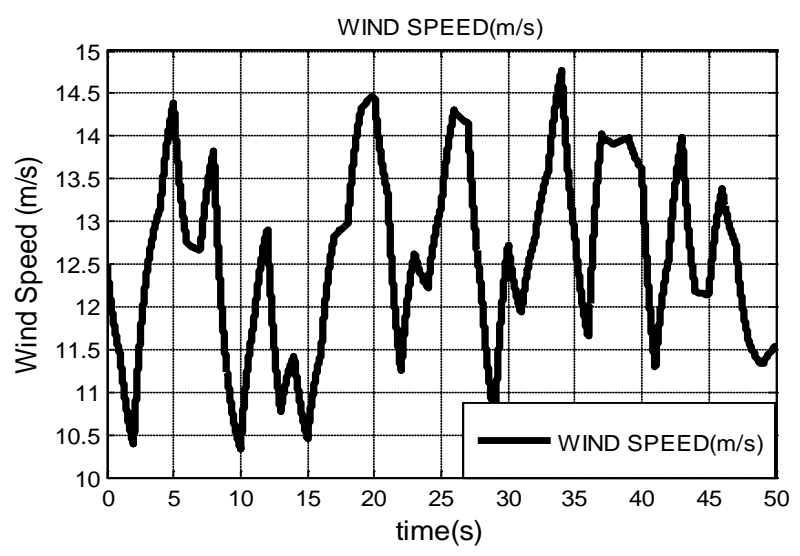

Figure 7. Simulated wind speed.

is observed that with the proposed strategy, the system is stable which verifies the effectiveness of the proposed control strategy. Also, the figure indicates that even though the wind speed changes, the presence of wind turbine lead to enhancement the system performance with the propose PI-MPC controller, significantly.

\section{Conclusion}

This paper investigates robust frequency control of a 


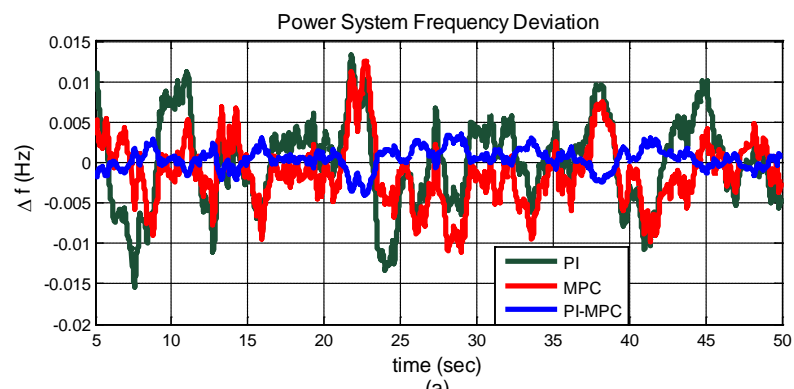

(a)

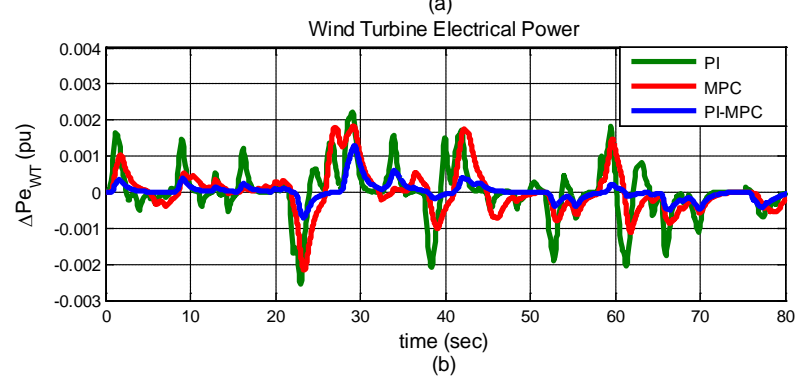

Figure 8. Power system response to variable wind speed: (a) frequency deviation $\Delta f$ and (b) WT electrical power output.

single area power system in the presence of wind farm based on the PI-MPC control technique. Digital simulations have been carried out in order to validate the effectiveness of the proposed scheme. The proposed controller has been tested for several mismatched parameters and load disturbance. Simulation results show that fast response, robustness against parameter uncertainties and load changes can be considered as some advantages of the proposed PI-MPC controller. In addition, a performance Comparison between the proposed controller and both the MPC and a conventional PI control schemes are carried out. It is shown that the PI-MPC controller response is much more effective than that of the traditional PI only and MPC only responses; and it is able to deal with both uncertainties in parameters and load changes more efficiently. Also, it is observed that both the MPC and the proposed PI-MPC controllers are robust, but the PI-MPC technique has the advantage over MPC with respect to faster oscillation damping, reducing variations, frequency enhancement and economics.

\section{References}

[1] P. Kundur, "Power System Stability and Control," McGraw-Hill, New York, 1994, pp. 581-585.

[2] H. Bevrani, "Robust Power System Control," Springer, New York, 2009, pp. 15-61. http://dx.doi.org/10.1007/978-0-387-84878-5

[3] K. Y. Lim, Y. Wang and R. Zhou, "Robust Decentralized load-frequency control of multi-area power systems,” IEE Proceedings of Generation, Transmission and Distribution, Vol. 143, No. 5, 1996, pp. 377-386. http://dx.doi.org/10.1049/ip-gtd:19960452

[4] H. Saadat, "Power System Analysis," McGraw-Hill, New
York, 1999, pp. 526-528.

[5] BTM Consult APS, "International Wind Energy Development World Market Update 2005, forecast 2006-2010,” 2006. Accessed 28 June.

http://www.btm.dk/Documents/Pressrelease.pdf.

[6] L. Holdsworth, J. B. Ekanayake and N. Jenkins, "Power System Frequency Response from Fixed Speed and Doubly Fed Induction Generator-Based Wind Turbines," Wind Energy, Vol. 7, No. 1, 2004, pp. 21-35. http://dx.doi.org/10.1002/we.105

[7] A. Mullane and M. O’Malley, “The inertial response of induction-machine-based wind turbines," IEEE Transactions on Power Systems, Vol. 20, No. 3, 2005, pp. 14961503. http://dx.doi.org/10.1109/TPWRS.2005.852081

[8] H. J. Lee, J. B. Park and Y. H. Joo, "Robust LFC for Uncertain Nonlinear Power Systems: A Fuzzy Logic Approach,” Information Science, Vol. 176, 2006, pp. 35203537. http://dx.doi.org/10.1016/j.ins.2006.01.003

[9] D. Rerkpreedapong, A. Hasanovic and A. Feliachi, "Robust Load Frequency Control Using Genetic Algorithms and Linear Matrix Inequalities,” IEEE Transactions on Power Systems, Vol. 18, No. 2, pp. 855 -861, 2003. http://dx.doi.org/10.1109/TPWRS.2003.811005

[10] A. Demiroren, H. L. Zeynelgil and N. S. Semgor, “The Application of ANN Technique to Load-Frequency Control for Three-Area Power System,” Paper accepted for presentation at PPT 2001, 2001 IEEE Porto Power Tech conference 10th-13th September, Porto, Portugal.

[11] F. Liu, Y. H. Song, J. Ma, S. Mai and Q. Lu, "Optimal Load-Frequency Control in Restructured Power Systems,” IEE Proceedings of Generation, Transmission and Distribution, Vol. 150, No. 1, 2003, pp. 87-95. http://dx.doi.org/10.1049/ip-gtd:20020683

[12] Y. Wang, D. J. Hill and G. Guo, "Robust Decentralized Control for Multimachine Power System,” IEEE Transactions on Circuits and Systems: Fundamental Theory and Applications, Vol. 45, No. 3, 1998.

[13] A. M. Stankovic, G. Tadmor and T. A. Sakharuk, "On Robust Control Analysis and Design for Load Frequency Regulation,” IEEE Transactions on Power Systems, Vol. 13, No. 2, 1998, pp. 449-455. http://dx.doi.org/10.1109/59.667367

[14] C. T. Pan and C. M. Liaw, "An Adaptive Controller for Power System Load-Frequency Control,” IEEE Transactions on Power Systems, Vol. 4, No. 1, 1989, pp. 122-128. http://dx.doi.org/10.1109/59.32469

[15] M. T. Alrifai and M. Zrib, "Decentralized Controllers for Power System Load Frequency Control,” ASCE Journal, Vol. 5, No. 2, June 2005.

[16] H. Bevrani, Y. Mitani and K. Tsuji, "Robust AGC: Traditional structure versus restructured scheme,” Transactions of Electrical Engineering in Japan, Vol. 124-B, No. 5, May 2004.

[17] E. Cam and I. Kocaarslan, "Load Frequency Control in Two Area Power Systems Using Fuzzy Logic Controller," Energy Conversion Management, Vol. 46, 2005, pp. 233243. http://dx.doi.org/10.1016/j.enconman.2004.02.022

[18] A. P. Birch, A. T. Sapeluk and C. S. Ozveren, "An En- 
hanced Neural Network Load Frequency Control Technique," Conference Publication No. 389, International Conference on Control, Coventry, UK, 21-24 March 1994, pp. 409-415.

[19] Y. L. Abdel-Magid and M. M. Dawoud, "Genetic Algorithms Applications in Load Frequency Control," Genetic Algorithms in Engineering Systems: Innovations and Applications, Conference Publications No. 414, IEE, 12-14 September 1995, 1995.

[20] J. Thomas, D. Dumur, J. Buisson and H. Gueguen, "Model Predictive Control for Hybrid Systems under a State Partition based MLD Approach (SPMLD)," International Conference on Informatics in Control, Automation and Robotics ICINCO’04, Vol. 3, Setúbal, pp. 78-85.

[21] J. Richalet, A. Rault, J. L. Testud and J. Japon, "Model Predictive Heuristic Control: Application to Industrial Processes," Automatica, Vol. 14, No. 5, 1978, pp. 413428. http://dx.doi.org/10.1016/0005-1098(78)90001-8
[22] C. W. De Silva, "Mechatronic Systems: Devices, Design, Control, Operation and Monitoring," Taylor and Francis Group, LLC, 2008.

[23] T. H. Mohamed, H. Bevrani, A. A. Hassan and T. Hiyama, "Model Predictive Based Load Frequency Control Design,” 16th International Conference of Electrical Engineering, Busan, Korea, July 2010.

[24] Y. S. Qudaih, M. Bernard, Y. Mitani and T. H. Mohamed, "Model Predictive Based Load Frequency Control Design in the Presence of DFIG Wind Turbine," Proceeding of the 2nd International Conference on Electric Power and Energy Conversion Systems (EPECS'11), Sharjah, UAE, 15-17 Nov. 2011.

[25] J. Morel, H. Bevrani, T. Ishii and T. Hiyama, “A Robust Control Approach for Primary Frequency Regulation through Variable Speed Wind Turbines,” IEEJ Transactions on Power and Energy, Vol. 130, No. 11, 2010, pp. 1002-1009. 